\title{
Vascular effects and dose-effect relationship of higher-dose oxytocin on adenomyosis: a randomized controlled trial
}

Junshu Li ( $\square$ 750400125@qq.com )

Mianyang Central Hospital https://orcid.org/0000-0001-9280-2032

Yong Wang

Mianyang Central Hospital

Liang $\mathrm{Hu}$

Chongqing Medical University

Rong Zhang

Chongqing Medical University

Jinyun Chen

Chongqing Medical University

Wenzhi Chen

Chongqing Medical University

\section{Research}

Keywords: Oxytocin(OT), Adenomyosis, Blood flow volume, Color Doppler ultrasound

Posted Date: May 14th, 2021

DOl: https://doi.org/10.21203/rs.3.rs-483260/v1

License: (c) (i) This work is licensed under a Creative Commons Attribution 4.0 International License. Read Full License 


\section{Abstract \\ Objective}

To assess the changes of blood flow in adenomyosis after higher-dose oxytocin(OT) in different doses, and to evaluate the safety for patients.

\section{Methods}

A total of 124 patients with adenomyosis were randomly divided into four groups with continuous intravenous infusion of oxytocin as $0.06 \mathrm{U} / \mathrm{min}, 0.12 \mathrm{U} / \mathrm{min}, 0.24 \mathrm{U} / \mathrm{min}$ and $0.36 \mathrm{U} / \mathrm{min}$, respectively. The changes of arteries of adenomyosis before and after intravenous infusion of OT were observed by color Doppler ultrasound. The changes of blood flow volume of artery of adenomyosis before and after intravenous infusion of OT were compared among the four groups, and the vital signs and adverse drug reactions were monitored during intravenous drip.

\section{Results}

During the trial, no severe adverse reactions occurred and the vital signs of all the patients were stable. In the four groups of patients, compared with those before intravenous infusion of OT, except that there was no significant difference in the diameter of vessels around the lesion and the peak blood flow velocity within the lesion in the $0.06 \mathrm{U} / \mathrm{min}$ OT intravenous drip group (P凶0.05), the peak blood flow velocity, mean blood flow velocity, vascular diameter and blood flow volume decreased after intravenous drip of OT, while the resistance index increased, and the difference was statistically significant (Pख0.05). Among the four groups, it was found that there was significant difference in the change of blood flow volume of blood artery in adenomyosis lesions between $0.06 \mathrm{U} / \mathrm{min}$ OT group and the other three groups after intravenous drip of OT(P凶0.05), but there were no significant difference in blood flow volume among the three groups $(P \otimes 0.05)$, and the difference of adverse drug reactions was statistically significant with the increase of OT dose (Pष0.05).

\section{Conclusion}

Oxytocin can effectively reduce the blood flow volume of adenomyosis lesions, and continuous intravenous infusion of $0.12 \mathrm{U} / \mathrm{min}$ OT is an appropriate dose that can not only minimize the blood flow volume but also reduce the incidence of adverse drugreactions.

\section{Trial registration}

: Chinese Clinical Trial Registry (NO.ChiCTR1800017048). 


\section{Background}

Adenomyosis (AM) is a common disease in women of childbearing age, which causes menorrhagia, severe dysmenorrhea and infertility, making a serious impact on the physical and mental health of patients ${ }^{1-3}$. At present, the clinical treatment for adenomyosis is limited, among which the traditional hysterectomy is the main means. The management for patients who want to preserve their reproductive function is difficult and complex in the field of gynecology, and the recurrence rate is high ${ }^{4-5}$. In recent years, with the continuous application of minimally and non-invasive methods in the treatment of adenomyosis, which achieved good results, and put forward new ideas to conservative treatment of adenomyosis. Among them, high-intensity focused ultrasound (HIFU) is the focus of related research. HIFU is a novel technology, which makes use of the physical characteristics of ultrasound to cause coagulative necrosis of the lesion tissue without damaging the surrounding normal organ, so as to achieve the purpose of reducing the size of the uterus and relieving related symptoms, enabling patients to avoid invasive treatment such as hysterectomy. A large number of clinical studies have confirmed that HIFU can effectively control the growth of lesions and alleviate clinical symptoms in patients with symptomatic adenomyosis ${ }^{6-8}$. However, the duration of symptom relief and re-intervention after HIFU are closely related to the ablation rate of adenomyosis, among which, the rich blood supply of lesion is an important factor affecting the ablation effect ${ }^{9}$. Therefore, to explore a method that can effectively reduce the blood supply of the lesions and improve the ablation rate is very important for the HIFU treatment of adenomyosis.

Oxytocin(OT) is the earliest discovered and synthesized neuropituitary hormone, which promotes uterine smooth muscle contraction mainly through the combination of OT and OT receptor (OTR). It is widely used in obstetrical fields such as induced labor, and postpartum hemorrhage. There are great individual differences in sensitive threshold and inactivation rate in vivo during intravenous infusion of OT, so there is no standard dose, safe dose and dangerous dose for clinical application of OT. In the treatment of postpartum hemorrhage, intramuscular injection of OT $10 \mathrm{U}$ is recommended, followed by continuous intravenous infusion of $10-20 \mathrm{U}$ with $500 \mathrm{ml}$ crystal solution. The conventional recommended speed is $250 \mathrm{ml} / \mathrm{h}$, which is about $80 \mathrm{mU} / \mathrm{min}$, and the total amount of $24 \mathrm{~h}$ should be controlled within $60-80 \mathrm{U}^{10-}$ ${ }^{12}$. However, the lowest effective dose of OT for the treatment of uterine atony is still being explored.

With the discovery of OTR in the non-gestational uterusOT has been used to promote uterine contraction of women with menorrhagia to reduce the amount of bleeding .OT has also been used to promote uterine contractions and reduce bleeding in laparoscopic or open myomectomy. In recent years, OT has also been used in HIFU ablation for uterine fibroids and adenomyosis to reduce the blood perfusion in the target area in real time and improve the acoustic environment to make ultrasonic energy deposition more effective ${ }^{13-15}$.Zhang Xin et al. ${ }^{16}$ compared the effect of intravenous infusion of OT and glucose on ultrasonic ablation for adenomyosis and the results showed that intravenous infusion of OT could effectively improve the non-perfused volume (NPV) rate and shorten the treatment time, but the ablation efficiency could not be improved with the increase of intravenous drip dose of OT $(0.32 \mathrm{U} / \mathrm{min}$ or 
$0.48 \mathrm{U} / \mathrm{min})^{17}$, and there is a lack of research comparison in lower dose group. With the saturation of OTR, stepping up the dose of OT may increase the adverse drug reactions. Therefore, the appropriate dose of OT that can effectively reduce the blood supply of adenomyosis and the adverse reactions is still unclear. On this basis, this study further explored the difference of lower dose of OT in reducing the blood supply of adenomyosis, in order to provide the basis for the dose selection of OT in ultrasound ablation of adenomyosis.

\section{Materials And Methods}

\subsection{Subjects}

A total of 124 patients were diagnosed with adenomyosis by gynaecologist and radiologist based on clinical presentation and magnetic resonance imaging (MRI) in the First Affiliated Hospital of Chongqing Medical University from July 10, 2018 to January 10, 2019.They were randomly divided into groups A, B, $\mathrm{C}$ and $\mathrm{D}$ according to the double blind method. Neither the patient nor the measurer was aware of the groups they are included in. The inclusion criteria were as follows:(1) localized adenomyosis with uterine wall thickness $\geq 30 \mathrm{~mm}$; (2) Color Doppler flow imaging(CDFI) can show obvious blood flow signal and collect blood flow index in adenomyosis lesion; (3) patients who agree to participate in the OT test. Exclusion criteria:(1)Patients with severe organic diseases of important organs: malignant hypertension, a history of myocardial infarction, heart failure, liver and kidney failure, etc; (2) Patients with a history of allergy to OT or multiple drug allergies( $\geq 2$ drugs) ; (3) Patients also with uterine fibroids. This study was approved by the Ethics Committee of Chongqing Medical University (Approval number: 2016016).It was registered in the Chinese Clinical Trial Registry (registration number: ChiCTR1800017048).All methods were carried out in accordance with the approved ethical guidelines. All patients had signed written informed consent forms.

\subsection{Instruments and Drugs}

Philips HD3 color Doppler ultrasound diagnostic system(Philips, USA.) was used. The probe frequency was $3.5 \mathrm{MHz}$ and the depth range was $15 \mathrm{~cm}$, and the gray gain was $0 \sim 50 \mathrm{~dB}$.The color Doppler gain is adjusted to $50 \mathrm{~dB}$. The pulse Doppler gain is $4-5 \mathrm{~dB}$. The sampling volume is $2-3 \mathrm{~mm}$, and the angle between the sound beam and the blood flow is less than $60^{\circ}$.OT (China Shanghai Shangyao First Biochemical Pharmaceutical Co.Ltd.Specifications: $1 \mathrm{ml}$ : 10U).

\subsection{Methods}

Color or power Doppler ultrasound was used to assess the direction of blood flow and vascular parameters ${ }^{18}$.After the lesion of adenomyosis was clearly displayed by two-dimensional ultrasound, then convert to color energy Doppler ultrasound mode, and the energy box contains the tissue of the lesion and the normal myometrium of $3 \mathrm{~mm}$ outside the lesion, then carefully observe the distribution characteristics of blood flow in the lesions. The artery with the largest diameter and the most obvious pulsation inside and around the lesion was selected. The diameter of the artery was measured, and then the sampling 
volume was placed in the center of the artery, and pulse Doppler ultrasonography mode was used to measure the relevant vascular parameters, including the peak systolic velocity (PSV), mean velocity (Vmean), and resitstance index (RI). The intravenous infusion of OT was adjusted to $30 \mathrm{drops} / \mathrm{min}$. Group A, group B, group C and group D were given $0.06 \mathrm{U} / \mathrm{min}, 0.12 \mathrm{U} / \mathrm{min}, 0.24 \mathrm{U} / \mathrm{min}$ and $0.36 \mathrm{U} / \mathrm{min}$, respectively. The body weight of all patients was recorded before and after OT test, and the adverse reactions were observed and recorded at the beginning of drip. The diameters and vascular parameters of peripheral and internal arteries obtained before OT infusion were measured again in the same way under the same conditions after infusion of $20 \mathrm{~min}$, and the parameters were consistent in the whole process of ultrasonic measurement by a single operator (JS.L.). During the whole process of OT test, the vital signs of patients were dynamically observed by electronic ECG monitor. Systolic blood pressure, diastolic blood pressure, mean arterial pressure and heart rate were recorded $5 \mathrm{~min}$ before OT, $0 \mathrm{~min}$ after OT, $5 \mathrm{~min}$ after $\mathrm{OT}, 10 \mathrm{~min}$ after $\mathrm{OT}, 20 \mathrm{~min}$ after $\mathrm{OT}, 5 \mathrm{~min}$ after stopping drip and $10 \mathrm{~min}$ after stopping drip, respectively. The dose-effect relationship of different doses of OT on blood vessels was compared by calculating the changes of blood flow volume. The calculation formula of blood flow volume was as follows: $Q=\pi \times R$

${ }^{2} \times \mathrm{V}$, where $\mathrm{R}$ is the radius of blood vessels and $\mathrm{V}$ is the average blood flow velocity.

\subsection{Statistical analysis}

SPSS20.0 software was used for data analysis. After testing, the measurement data of normal distribution was expressed by mean \pm standard deviation ( $X \pm S), T$ test or chi-square test. Repeated measurement analysis of variance was used for vital signs. In univariate analysis, the chi-square test or Fisher exact probability was used for classified variables. Univariate regression analysis was used for quantitative data, and multivariate regression analysis was performed for univariate factors with statistical differences. $P<0.05$ was statistically significant.

\section{Results}

2.1 General information of patients

All 124 patients received OT test with an average age of $40.5 \pm 5.5$ (25- 53) years old, and an average body mass index of $22.8 \pm 3.1(16.5-31.9) \mathrm{kg} / \mathrm{m}^{2}$ mong them 6 patients were complicated with single underlying diseases, including hypertension ( 1 case), hepatitis B virus carriers (1 case), hypothyroidism ( 2 cases), chronic peptic ulcer (1 case), and asthma (1 case).Fifteen cases had a history of drug allergy, including penicillin (4 cases), cephalosporin ( 3 cases), sulfonamide ( 1 case), metronidazole ( 1 case), $\beta$-lactam drugs ( 1 case), misoprostol (1 case), high protein ( 2 cases), cosmetics (1 case) and mango (1 case). There was no significant difference in age, body mass index, underlying disease and allergy history among the four groups $(P>0.05)$. See table 1 .

2.2 Characteristics of color Doppler ultrasonography

The distribution of blood flow signal in the lesion was similar to that in the myometrium, and the difference is not obvious. The blood flow signal in the periphery of the focus is reticular or short linear, 
while in the internal of the focus were dot-like, short-line, small reticular dense and diffuse. After intravenous infusion of OT: the peripheral blood supply of focus disappeared completely by $4.0 \%(5 / 124)$ and decreased by $91.9 \%$ (114/124); the internal blood supply completely disappeared by $12.1 \%(15 / 124)$ and decreased by $79.8 \%(99 / 124)$. See figure 1 .

\subsection{Vascular parametersof adenomyosis}

Compared with those before OT, the changes of vascular parameters of arteries in peripheral and internal of adenomyosis in the four groups with different OT doses showed significant differences after the administration of OT(Pख0.05).Except for the changes of peripheral vascular diameter and internal peak blood flow velocity in $0.06 \mathrm{U} / \mathrm{min}$ OT group, there was no significant difference $(P>0.05)$. The diameter of other blood vessels decreased, resistance index increased, blood flow velocity decreased, blood flow decreased, and the difference was statistically significant $(P<0.05)$. See figure 2 and figure 3 .

2.4 Comparison of blood flow changes of artery with different doses of OT.

The blood flow volume after intravenous infusion of OT of both the peripheral and internal arteries of the adenomyosis in the four groups decreased, and there was significant difference (Pख0.05). The changes of blood flow volume of peripheral and internal arteries of the four groups before and after intravenous drip of OT were compared. It was found that only the change of blood flow volume in the $0.06 \mathrm{U} / \mathrm{min}$ intravenous drip group was significantly different from the other three groups(P凶0.05). Increasing the dose on the basis of $0.12 \mathrm{U} / \mathrm{min}$, any significant difference in the change of blood flow volume among the other three groups was not found (Pख0.05).See figure 4.

\subsection{Adverse reactions}

No severe adverse events occurred. Among the 124 patients, the vital signs were relatively stable and fluctuated within the normal range during the whole test(Pख0.05).Among them, 24 cases had adverse drug reactions, including craniofacial fever $(n=14)$, uterine contraction pain $(n=15)$, chest tightness $(n=3)$, diarrhea $(n=1)$ and stomach discomfort $(n=2)$. Among the 15 patients with uterine contraction pain, only one patient developed progressive aggravation during intravenous drip of OT $0.12 \mathrm{U} / \mathrm{min}$ and disappeared spontaneously after $10 \mathrm{~min}$ of stopping the infusion of OT. The symptoms of 24 patients with adverse reactions disappeared spontaneously during intravenous drip and after $20 \mathrm{~min}$ of stopping intravenous drip. The incidences of adverse reactions occurred in groups of $0.06 \mathrm{U} / \mathrm{min}, 0.12 \mathrm{U} / \mathrm{min}$, $0.24 \mathrm{U} / \mathrm{min}$ and $0.36 \mathrm{U} / \mathrm{min}$ were $9.7 \%(3 / 31), 9.7 \%(3 / 31), 19.4 \%(6 / 31)$ and $38.7 \%(12 / 31)$, respectively. There was significant difference in the incidence of adverse reactions among groups with different doses of OT $(P<0.05)$. The adverse reactions ranged from mild to moderate level and there was no significant difference in the degree of adverse reactions among different dose groups(Pख0.05).Multivariate regression analysis showed that only the dose of OT $(B=0.019, P=0.005)$ and an allergic history $(B=-3.023, P=0.000)$ had significant effects on the occurrence of adverse reactions $(P<0.01)$.

\section{Discussion And Conclusion}


OT is a kind of circular nine-peptide amino acid, which is mainly secreted by hypothalamus and widely distributed in organs of human body. As an effective uterine contractile agent, it is widely used to induce labor, prevent postpartum hemorrhage and play a role in other obstetrical fields. Richer 0 et al. ${ }^{19}$ found that OT receptor exists not only in the uterus of pregnant women, but also on the surface of uterine smooth muscle cells of non-pregnant uterus. Weston GC et al. ${ }^{20}$ further found that there are OT receptors in uterine macrovascular endothelial cells and microvessels of uterine myometrium, which provides a basis for the use of OT in the treatment of gynecological diseases. Through systematic review and metaanalysis of 26 randomized controlled trials, Samy An et al. ${ }^{21}$ found that OT infusion is the most effective hemostatic method in minimally invasive myomectomy compared with open myomectomy. Zhang Xin et al. ${ }^{16-17}$ further confirmed that OT in ultrasonic ablation of adenomyosis can effectively reduce the energy for ultrasonic ablation of adenomyosis and shorten the treatment time, but increasing the dose of OT to $0.48 \mathrm{U} / \mathrm{min}$ further on the basis of intravenous drip of $0.32 \mathrm{U} / \mathrm{min}$ OT cannot improve the efficiency of ultrasonic ablation, and a lower effective dose of OT has not been explored. Although there were no severe adverse reactions occurred in all the subjects in this study, multiple factors interfered in the observation of adverse reactions of $\mathrm{OT}$, such as sedative and analgesic drugs used in the treatment of HIFU. Therefore, for the safety and efficacy of this study, we further explore the safety of single-factor intravenous drip of OT and the dose-effect relationship of lower dose of OT on the blood vessels of adenomyosis, so as to find a more suitable, safe and effective dose for ultrasonic ablation of adenomyosis. In this study, the changes of blood flow index of artery in the cases of adenomyosis were measured by color Doppler ultrasonography before and after intravenous infusion of OT. The results showed that after intravenous infusion of $0.06 \mathrm{U} / \mathrm{min}, 0.12 \mathrm{U} / \mathrm{min}, 0.24 \mathrm{U} / \mathrm{min}$ and $0.36 \mathrm{U} / \mathrm{min} \mathrm{OT}$, the average blood flow velocity decreased, RI increased, diameter decreased and blood flow volume decreased. The changes of blood flow volume in the internal and peripheral arteries of the four groups were compared before and after intravenous infusion of OT. $t$ was found that there was significant difference in the change of blood flow volume between the $0.06 \mathrm{U} / \mathrm{min}$ intravenous drip group and the other three groups, but there was no significant difference among $0.12 \mathrm{U} / \mathrm{min}, 0.24 \mathrm{U} / \mathrm{min}$ and $0.36 \mathrm{U} / \mathrm{min}$ groups. That means, continuous intravenous drip of OT dose of $0.12 \mathrm{U} / \mathrm{min}$ can minimize the blood flow of the internal and peripheral arteries of the adenomyosis, while increasing the OT dose cannot further reduce the blood flow volume of the adenomyosis, and with the increase of OT drip dose, the incidence of adverse reactions in the four groups were $9.7 \%(3 / 31), 9.7 \%(3 / 31), 19.4 \%(6 / 31)$ and $38.7 \%(12 / 31)$, respectively. Thus it can be seen that the incidence of adverse drugreactions rises with the increase of intravenous drip dose of OT. It can also be found that continuous intravenous drip with $0.12 \mathrm{U} / \mathrm{min}$ OT is a safe and effective dose which can reduce the blood flow volume of adenomyosis.

In this study, $83.3 \%$ of OT adverse reactions occurred in patients $\geq 35$ years old to premenopausal, which may be related to the fluctuation of hormone secretion and decreased tolerance in women of this age group, but there were no severe adverse reactions occurred. It has been reported that the sensitivity of OT receptor to OT is regulated by the level of estrogen in vivo, and estrogen can improve the sensitivity of OT receptor to $\mathrm{OT}^{22}$. With the increase of age, the hormone secretion of physiological level in the body also fluctuates greatly, older people are more likely to have adverse drug reactions. In addition, the analysis of 
the influencing factors of adverse drug reactions of OT showed that the occurrence of adverse reactions was mainly related to the dose of OT and an history of allergy $(P<0.05)$. Therefore, attention should be paid to the safety of drug use in patients with allergic constitution in clinical practice. Although the dose of OT in this study has exceeded the application scope of OT drug instructions in obstetrics, the incidence of adverse drug reactions caused by intravenous administration of OT was significantly lower than that caused by obstetrical use of OT ( $19.4 \%$ vs $14-77.5 \%)^{23-25}$, This may be related to the significantly lower level of OT receptor distribution in non-pregnant women than in pregnant women ${ }^{19-20}$.All of the 24 adverse drug reaction in this study were not life-threatening, and they disappeared in $20 \mathrm{~min}$ after stopping infusion of OT.

In this study, due to the targeted subject and the small sample size of each group, a prospective randomized controlled trial with large samples is needed to verify the study results in the next stage. The effect of different operators and different instruments on the results also requires further multicenter randomized controlled trial. Further studies need to be conducted to determine whether factors such as ovarian cycle and reproductive history during intravenous infusion of OT will affect the expression of OT receptor.

In conclusion, OT can effectively reduce the blood flow volume of adenomyosis lesions in non-pregnant women. Intravenous infusion of OT with $0.12 \mathrm{U} / \mathrm{min}$ may be the appropriate dose to reduce the blood supply of adenomyosis lesions with the minimal adverse reactions.

\section{Declarations}

\section{Acknowledgments}

We are grateful to all the participants involved in this study.

\section{Funding}

None

\section{Availability of data and materials}

The datasets used and/or analysed during the current study are available from the corresponding author upon reasonable request.

\section{Authors' contributions}

$\mathrm{JL}$ wrote the main manuscript and analyzed the data.LH and RZ organized the study.JL and YW collected the data.JC and WC conceived and designed the study.All authors approved the final manuscript.

\section{Ethics approval and consent to participate}


This study was approved by the ethics committee of Chongqing Medical University, and that the study has adhered to the Declaration of Helsinki.

\section{Consent for publication}

Written informed consent for publication was obtained from the patients.

\section{Competing interests}

The authors declare that they have no competing interests.

\section{Authors' information}

${ }^{1}$ State Key Laboratory of Ultrasound in Medicine and Engineering, College of Biomedical Engineering, Chongqing Medical University,Chongqing,400016, China;

2Department of Obsterics and Gynecology, Chongqing Haifu Hospital, Chongqing 401121,Peoples' Republic of China;

${ }^{3}$ Ultrasound Ablation Center, 1 st Affiliated Hospital of Chongqing Medical University, Chongqing 400042, China;

${ }^{4}$ Department of Obstetrics and Gynecology, Mianyang Central Hospital, School of Medicine, University of Electronic Science and Technology of China, Mianyang, Sichuan, 621000, Peoples' Republic of China.

${ }^{5}$ Department of Ultrasound Diagnosis, Mianyang Central Hospital, School of Medicine, University of Electronic Science and Technology of China, Mianyang, Sichuan, 621000, Peoples' Republic of China.

\section{Abbreviations}

OT:Oxytocin

AM:Adenomyosis

HIFU:High-intensity focused ultrasound

PSV:peak systolic velocity

Vmean:mean velocity

Rl:resitstance index

\section{References}


[1] Lacheta J.Uterine adenomyosis: pathogenesis,diagnositics,symptomatology and treatment.Ceska Gynekol.2019 Spring;84(3):240-246.

[2] Buggio L, Monti E, Gattei U, Dridi D, Vercellini P. Adenomyosis: fertility and obstetric outcome. A comprehensive literature review. Minerva Ginecol. 2018 Jun;70(3):295-302.

[3] Naftalin J, Hoo W, Nunes N, Holland T, Mavrelos D, Jurkovic D. Association between ultrasound features of adenomyosis and severity of menstrual pain. Ultrasound Obstet Gynecol. 2016 Jun;47(6):77983.

[4] Vannuccini S, Luisi S, Tosti C, Sorbi F, Petraglia F. Role of medical therapy in the management of uterine adenomyosis. Fertil Steril. 2018 Mar;109(3):398-405.

[5] Oliveira MAP, Crispi CP Jr, Brollo LC, Crispi CP, De Wilde RL. Surgery in adenomyosis. Arch Gynecol Obstet. 2018 Mar;297(3):581-589.

[6] Dueholm M. Minimally invasive treatment of adenomyosis. Best Pract Res Clin Obstet Gynaecol. 2018 Aug;51:119-137.

[7] Zhang L, Rao F, Setzen R. High intensity focused ultrasound for the treatment of adenomyosis: selection criteria, efficacy, safety and fertility. Acta Obstet Gynecol Scand. 2017 Jun;96(6):707-714.

[8] Yang X, Zhang X, Lin B, Feng X, Aili A. Combined therapeutic effects of HIFU, GnRH-a and LNG-IUS for the treatment of severe adenomyosis. Int J Hyperthermia. 2019;36(1):486-492.

[9]Gong C, Yang B, Shi Y, Liu Z, Wan L, Zhang H, Jiang D, Zhang L. Factors influencing the ablative efficiency of high intensity focused ultrasound (HIFU) treatment for adenomyosis: A retrospective study. Int J Hyperthermia. 2016 Aug;32(5):496-503.

[10] Liu xing hui,Zhang li,Zhang jing.Interpretation of Guideline on the Prophylaxis and Treatment of Postpartum(2009 and 2014).Chin J Obstet Gynecol Pediatr(Electron Ed),August 2015,11(4):433-447.

[11] Deneux-Tharaux C, Sentilhes L, Maillard F, Closset E, Vardon D, Lepercq J, Goffinet F. Effect of routine controlled cord traction as part of the active management of the third stage of labour on postpartum haemorrhage: multicentre randomised controlled trial (TRACOR). BMJ. 2013 Mar 28;346:f1541.

[12] Leduc D, Senikas V, Lalonde AB; CLINICAL PRACTICE OBSTETRICS COMMITTEE. Active management of the third stage of labour: prevention and treatment of postpartum hemorrhage. J Obstet Gynaecol Can. 2009 Oct;31(10):980-993.

[13] Atashkhoei S, Fakhari S, Pourfathi H, Bilehjani E, Garabaghi PM, Asiaei A. Effect of oxytocin infusion on reducing the blood loss during abdominal myomectomy: a double-blind randomised controlled trial. BJOG. 2017 Jan;124(2):292-298. 
[14] Lozinski T, Filipowska J, Krol P, Kubaty A, Wegrzyn P. Oxytocin Administration in High-Intensity Focused Ultrasound Treatment of Myomata. Biomed Res Int. 2018 Jul 2;2018:7518026.

[15] Yu SC, Cheung EC, Leung VY, Fung LW. Oxytocin-Augmented and Non-Sedating High-IntensityFocused Ultrasound (HIFU) for Uterine Fibroids Showed Promising Outcome As Compared To HIFU Alone or Uterine Artery Embolization. Ultrasound Med Biol. 2019 Dec;45(12):3207-3213.

[16] Zhang X, Zou M, Zhang C, He J, Mao S, Wu Q, He M, Wang J, Zhang R, Zhang L. Effects of oxytocin on high intensity focused ultrasound (HIFU) ablation of adenomysis: a prospective study. Eur J Radiol. 2014 Sep;83(9):1607-11.

[17] Zhang X『He J,Mao SH,Wang J,Wu Q,Zhang RT,Zhang L.Dose-effect research on the effect of OT on high intensity focused ultrasound ablation of adenomysis. Laser J.2013 Oct;34(6):103-104.

[18] Van den Bosch T, Dueholm M, Leone FP, Valentin L, Rasmussen CK, Votino A, Van Schoubroeck D, Landolfo C, Installé AJ, Guerriero S, Exacoustos C, Gordts S, Benacerraf B, D'Hooghe T, De Moor B, Brölmann H, Goldstein S, Epstein E, Bourne T, Timmerman D. Terms, definitions and measurements to describe sonographic features of myometrium and uterine masses: a consensus opinion from the Morphological Uterus Sonographic Assessment (MUSA) group. Ultrasound Obstet Gynecol. 2015 Sep;46(3):284-98.

[19] Richter O, Wardelmann E, Dombrowski F, Schneider C, Kiel R, Wilhelm K, Schmolling J, Kupka M, van der Ven $\mathrm{H}$, Krebs D. Extracorporeal perfusion of the human uterus as an experimental model in gynaecology and reproductive medicine. Hum Reprod. 2000 Jun;15(6):1235-40.

[20] Weston GC, Cann L, Rogers PA. Myometrial microvascular endothelial cells express OT receptor. BJOG. 2003;110(2):149-156.

[21] Samy A, Raslan AN, Talaat B, El Lithy A, El Sharkawy M, Sharaf MF, Hussein AH, Amin AH, Ibrahim AM, Elsherbiny WS, Soliman HH, Metwally AA. Perioperative nonhormonal pharmacological interventions for bleeding reduction during open and minimally invasive myomectomy: a systematic review and network meta-analysis. Fertil Steril. 2020 Jan;113(1):224-233.e6.

[22] Murata T, Narita K, Ichimaru T. Rat uterine oxytocin receptor and estrogen receptor $a$ and $\beta$ mRNA levels are regulated by estrogen through multiple estrogen receptors. J Reprod Dev. 2014 Mar 7;60(1):5561.

[23] Bilgin Z, Kömürcü N. Comparison of the effects and side effects of misoprostol and OT in the postpartum period: A systematic review. Taiwan J Obstet Gynecol. 2019;58(6):748-756.

[24] Shrestha A, Dongol A, Chawla CD. Rectal misoprostol versus intramuscular OT for prevention of post partum hemorrhage. Kathmandu Univ Med J (KUMJ). 2011;9(33):8-12. 
[25] Atukunda EC, Siedner MJ, Obua C, Mugyenyi GR, Twagirumukiza M, Agaba AG. Sublingual misoprostol versus intramuscular oxytocin for prevention of postpartum hemorrhage in Uganda: a double-blind randomized non-inferiority trial. PLoS Med. 2014 Nov 4;11(11):e1001752.

\section{Table}

Tab.1 The characteristics of 124 patients with adenomyosis

\begin{tabular}{|c|c|c|c|c|c|}
\hline Variable & Group A & Group B & Group C & Group D & $P$-value \\
\hline $\begin{array}{l}\text { OT dose } \\
\text { (U/min) }\end{array}$ & 0.06 & 0.12 & 0.24 & 0.36 & 7 \\
\hline $\mathrm{N}$ & 31 & 31 & 31 & 31 & 1 \\
\hline Age\year】 & $\begin{array}{c}39.9 \pm 6.3 \\
025-53 \square\end{array}$ & $\begin{array}{c}41.7 \pm 4.4 \\
\square 34-49 \square\end{array}$ & $\begin{array}{c}40.6 \pm 6.1 \\
\square 28-51 \square\end{array}$ & $\begin{array}{c}39.2 \pm 5.0 \\
\square 29-48 \square\end{array}$ & 0.279 \\
\hline $\mathrm{BMI} \square \mathrm{kg} / \mathrm{m}^{2} \mathrm{\square}$ & $21.9 \pm 2.4 \square 17.7-2$ & $\pm 3.0 \square 16.5-$ & $\begin{array}{r}23.9 \pm 3.0 \\
\square 19.2-30.5 \square\end{array}$ & $\pm 3.0 \square 18.4$ & 0.051 \\
\hline Allergic history $\llbracket n \square$ & $1(3.2 \%)$ & $5(16.1 \%)$ & $4(12.9 \%)$ & $5(16.1 \%)$ & 0.380 \\
\hline Underlying disease $\llbracket n$ & $1(3.2 \%)$ & $1(3.2 \%)$ & $2(6.5 \%)$ & $2(6.5 \%)$ & 0.999 \\
\hline
\end{tabular}

NOTE: Date expressed as mean $\pm \mathrm{SD}$, and data in parentheses represents the range.

Abbreviations: $\mathrm{OT}=$ oxytocin, $\mathrm{BMI}=$ body mass index.

\section{Figures}

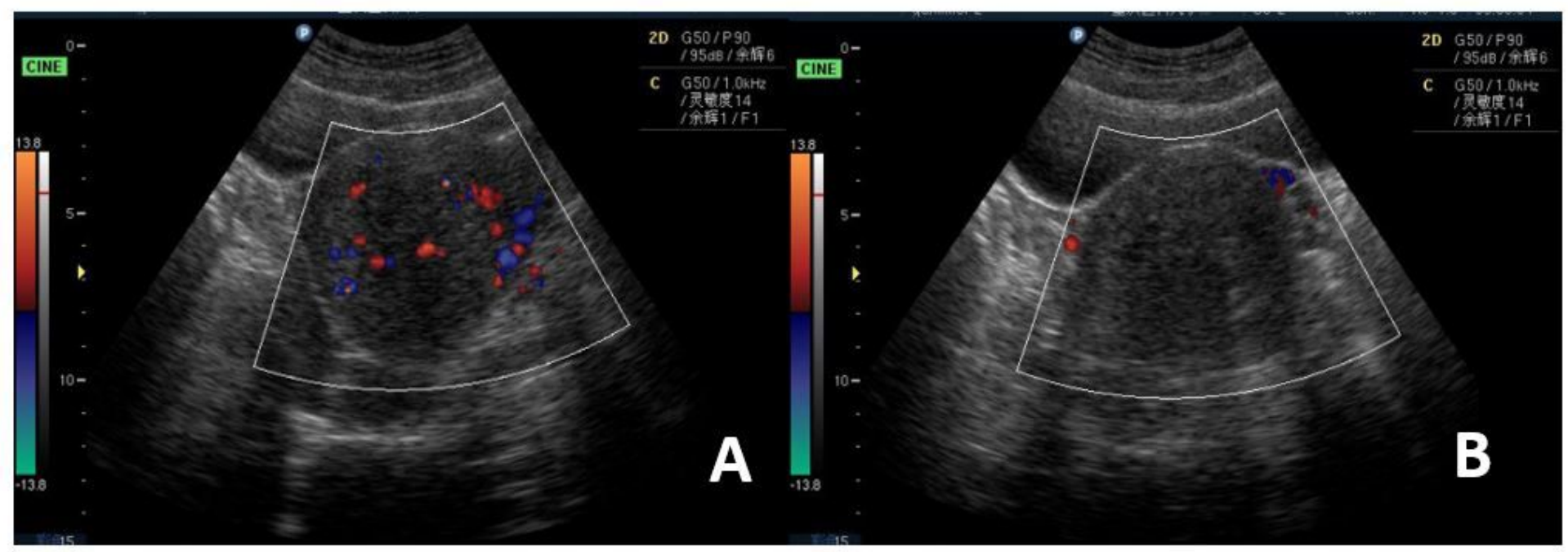

Figure 1 
Color Doppler ultrasonography of adenomyosis before(A) and ten minutes after(B) intravenous drip of oxytocin.
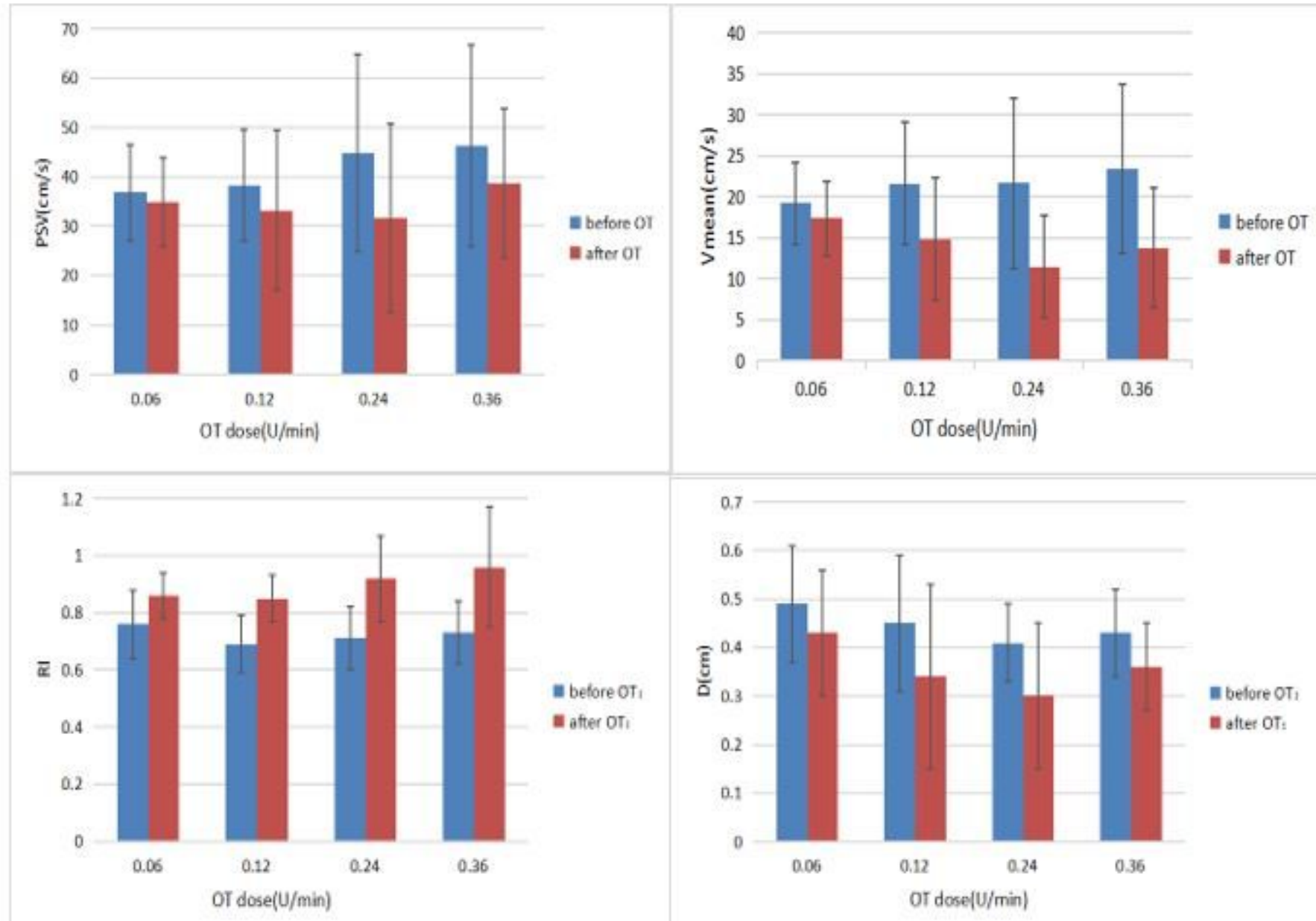

NOTE: There was no significant difference in the vessel diameter(D) after intravenous infusion of $0.06 \mathrm{U} / \mathrm{min}$ OT $(\mathrm{P}>0.05)$, while the remaining variables were statistically significant after infusion of OT $(P<0.05)$.

Figure 2

Changes of blood flow parameters before and after intravenous infusion of oxytocin in peripheral artery of adenomyosis. 

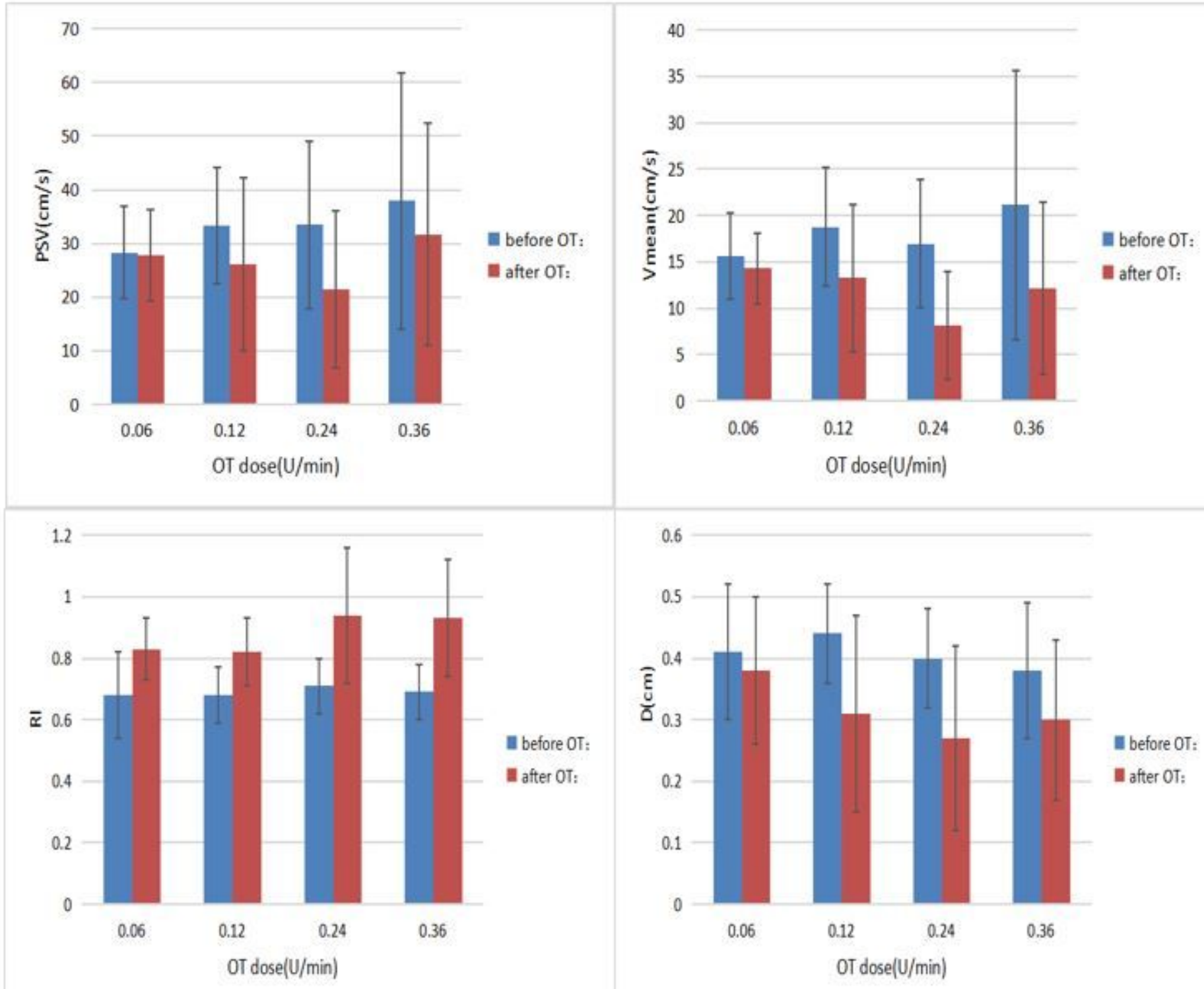

NOTE: There was no significant difference in the systolic peak velocity (PSV) after intravenous infusion of $0.06 \mathrm{U} / \mathrm{min}$ OT $(\mathrm{P}>0.05)$, while the remaining variables were statistically significant after infusion of OT $(\mathrm{P}<0.05)$.

\section{Figure 3}

Changes of blood flow parameters before and after intravenous infusion of oxytocin in internal artery of adenomyosis. 


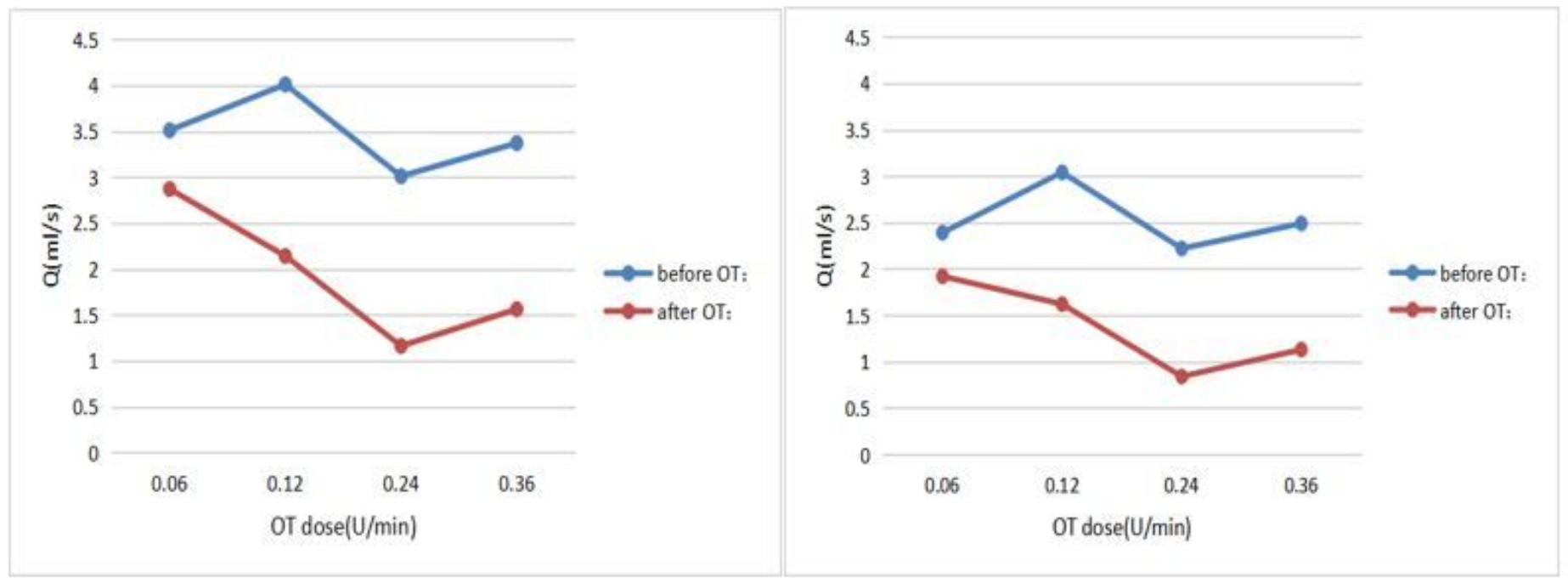

\section{Figure 4}

Changes of blood flow volume in peripheral arterial (left picture) and internal arterial (right picture) before and after intravenous infusion of oxytocin. 